\title{
Property level flood protection: technical insights of a new safety flood door
}

\author{
D. W. Beddoes \& C. A. Booth \\ Centre for Floods, Communities and Resilience, \\ University of the West of England, UK
}

\begin{abstract}
Governments acknowledge that many buildings cannot be protected from flooding by large-scale flood defence schemes and, therefore, property level flood protection is considered part of an integrated flood risk strategy, requiring homeowners to shoulder some of this responsibility and install appropriate resistance and resilience measures themselves. Whilst there are many products and options already available to homeowners, this study proposes a new safety flood door and frame (Patent Pending 1315021.4) that can be fitted into new or existing door apertures. The double rebated door is designed to open outwards and has an automatic safety flap that lets in floodwater when the differential height reaches a critical level $(600 \mathrm{~mm}$ depth) that may cause structural property damage. Furthermore, the water seals are enhanced by external water pressure from the floodwater and a safety outlet for floodwater trapped inside the building is fitted. From a commercial and practical perspective, the patented product demonstrates several advantages over those of existing flood door designs and systems and, moreover, is an affordable option by comparison to other flood doors.
\end{abstract}

Keywords: property adaptation, flood resistance, flood resilience, patent product.

\section{Introduction}

In England and Wales, the threat of flooding affects approximately five million homes (circa 1 in 6 properties) and climate change forecasts suggest these figures are likely to worsen over the coming decades [1-3]. In the face of such disturbing predictions, raising awareness of the responsibility for homeowners to 
provide their own property level flood protection is supported by national government strategies and incentives $[4,5]$.

A major source of water ingress into most flooded properties is through doorways. Therefore, there has been a great deal of development of aperture guards [6], which include temporary demountable guards that are fitted across doorways to prevent water entry. Unfortunately, temporary guards have many inherent problems, such as who will deploy them when homeowners are asleep, are they accessible at short notice, who deploys when people are at work, can the infirm fit them, are the edge seals intact, are the edge seals perished, are the fixing clips intact, with so many different types available - are they being correctly fitted, and are they simply missing or have they been stolen? Furthermore, property insurers are unlikely to consider demountable aperture guards when looking at flood insurance as they have no form of assurance that, come a flood event, the guards will have been fitted [7].

Flood proof external doors are also available but they have to be robust in construction with multiple locking mechanisms and, as such, are often bespoke and very expensive items. Also, a flood proof door will resist floodwater entry up to its full height of two metres and, as a consequence of withholding this depth of floodwater, may cause structural damage and collapse of the property itself (if there is no other means of floodwater entry). Research has shown that due to structural considerations there is a recommended limit to the height of floodwater that a typical masonry wall can support - this being $600 \mathrm{~mm}$ differential height between finished floor level inside the property and floodwater level outside [8].

This study presents a new safety flood door and frame (Patent Pending 1315021.4 [9]), which is affordable (compared to other commercially available flood doors) and offers property level flood protection as part of its design.

\section{Property level flood protection}

Avoidance must be the first pathway against flooding but this can be both complex and very expensive. Relocation is often impractical and the option of building in areas of low or no flood risk is a planning issue, which must be addressed prior to construction $[10,11]$. Therefore, it is often the case that homeowners need to deal with flooding issues themselves and are simply left with a choice of several flood resistance and resilience options to protect their homes [12]. Flood resistance involves the construction of a building in such a way as to prevent floodwater entering the property and damaging its fabric [13]. Flood resistance must always be installed as a complete package [14]. Every entry point for floodwater must be blocked as any small entry point will render a whole suite of resistance measures ineffective. Whereas, flood resilience involves constructing a building, or adapting an existing building, in such a way that, although floodwater may enter the property, its impact is minimised (i.e. no permanent damage is caused, structural integrity is maintained and drying and cleaning are facilitated) [2]. Flood resilience measures focus on reducing the overall damage caused and decreasing the recovery time. 
Whilst there are many products and options available to homeowners, there seems limited consideration of products that allow floodwater to enter a property when the differential height exceeds the recommended limit. To overcome this problem, this study introduces a new safety flood door and frame that can be fitted into new or existing door apertures, the double rebated door to open outwards and has an automatic safety flap that lets in floodwater when the differential height reaches a critical level that may cause structural property damage, the water seals at frame to brickwork and door to frame joins will be enhanced by external water pressure from the floodwater and a safety outlet for floodwater trapped inside the building may be fitted.

\section{Detailed and diagrammatic description of the new safety flood door}

The new safety flood door and frame is described by reference to the accompanying drawings: Figure 1a is a line drawing showing the door frame A to which the door B is pivotally attached. The frame A has a lip E that sits against the face of the brickwork $\mathrm{D}$ and during installation the join between $\mathrm{E}$ and the brickwork is sealed with waterproof sealant. The frame lip E ensures that any floodwater pressure exerted on the outside of the frame will serve to further compress the sealant and so increase the waterproof seal between frame and brickwork, this is in contrast to the normal procedure of mounting the frame inside the reveal of the brickwork aperture where it can be easily displaced and pushed into the property by the force of the floodwater.

The pivotally attached door B opens outwards from the property and so any hydrostatic pressure will further force the door against the frame and increase the effectiveness of the seal between them. The flap $\mathrm{C}$ is pivotally attached to cover an aperture that passes through the door B. Flap $\mathrm{C}$ is buoyant in the floodwater and will rise when the floodwater reaches it to let the water into the property so that no structural damage occurs. The door B, for the safety of the homeowner cannot be inadvertently opened into the face of the homeowner when water is rising outside the property. Door B can be fitted flush or set back into the frame rebate.

The pivotally hinged flap $\mathrm{C}$ ensures that there is no instant rush of water into the property that may be injurious to the homeowner, the buoyant flap $\mathrm{C}$ rises and floodwater ingress through the exposed door aperture behind it is controlled at a safe rate by the size of the aperture in the door. The pivotally hinged buoyant flap C can be fitted to any type of door: solid doors, transom doors as shown in the drawing and it can be retro-fitted to existing doors. If a door with a transom is used the lower panel can be solid to resist floodwater and floating debris, whist the upper panel could be glazed. Opening flap $\mathrm{C}$ can be inherently buoyant or have buoyancy items, such as cork attached. Flap $\mathrm{C}$ can also be used for postal deliveries and can be set at various heights. The one-way valve or simple plug $\mathrm{H}$ can be used after the floodwater recedes to let the remaining floodwater out of the property, rather than breaking through the lower door panel to produce a sudden and dangerous rush of escaping floodwater. 


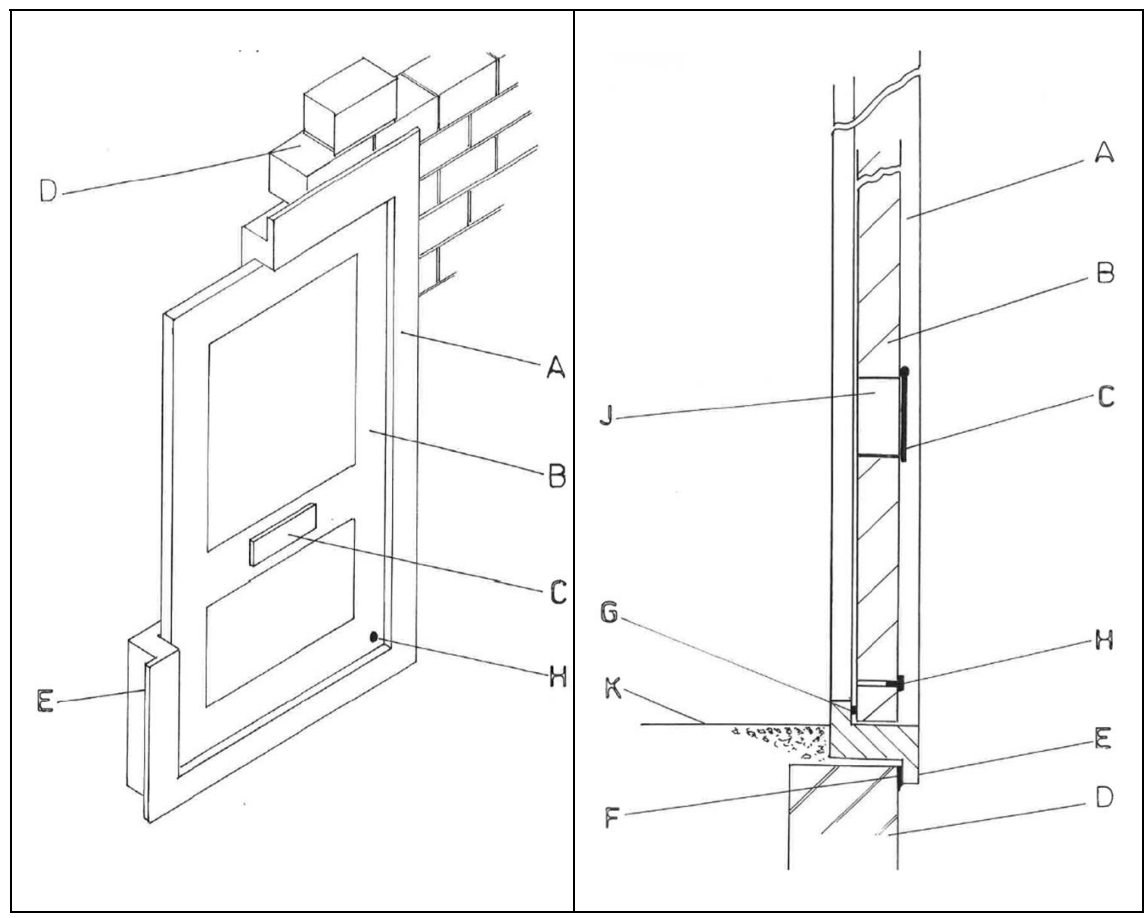

(a)

(b)

Figure 1: Sectional drawings of the safety flood door show (a) sketch of the door and frame set into the doorway of a property and (b) vertical cross-section through the central lower part of the door and frame.

Figure 1(b) shows a vertical cross-sectional line drawing through the central lower part of the frame and door when installed. The frame is shown as A with the door B pivotally linked to the frame so that it opens outwards from the property. As the door B opens outwards any floodwater pressure on the outside will increase the pressure on the seal $\mathrm{G}$ which sits between door $\mathrm{B}$ and frame $\mathrm{A}$ to further resist water ingress. The frame $\mathrm{A}$ has a lip $\mathrm{E}$ on the outside face and this lip E sits onto the outside front face of the brickwork D. The waterproof seal F sits between lip E and brickwork D and any floodwater pressure on the outside of the frame serves to exert extra force on this join and so make it more watertight. The lip E on the outside of the frame A does not have to be in place all around the whole perimeter of the frame as it only needs to make a watertight seal up to the height of floodwater to be resisted before floodwater is let in through the floating flap $\mathrm{C}$. An angled moulding could be fitted to a conventional external door frame over its lower area to similarly achieve a suitable lip E and an enhanced watertight join over the required lower section of the door frame. The lip E with waterproof sealant F applied between itself and the brickwork makes fitting the frame quick, robust, foolproof and watertight. In combination with a hydrophobic chemical treatment applied to the external masonry wall the 
installation of this invention will provide external floodwater resistance for some properties. The lip E and its waterproof fitting to the brickwork only need to extend up to the level of flap $\mathrm{C}$ as after this critical height the floodwater is let into the property.

The floating flap $\mathrm{C}$ is pivotally attached to the door $\mathrm{B}$ and covers an aperture $\mathrm{J}$ through the door $\mathrm{B}$. The buoyant flap $\mathrm{C}$ rises under the action of the floodwater and this allows floodwater to enter the property in a controlled manner through aperture J. The height difference between internal finished floor level $\mathrm{K}$ and lower edge of aperture $\mathrm{J}$ is the differential height at which floodwater is let into the property to prevent structural damage from excessive hydrostatic pressure. The differential height can be set by the level of aperture $\mathrm{J}$ and flap $\mathrm{C}$ and can vary in line with different structural strengths of external wall construction.

$\mathrm{H}$ is a one-way valve, or simple bung, it serves as a controlled method for releasing water that has become trapped inside the property after the outside floodwater recedes. In a flood event the opening of doors with water pressure pushing behind them is the cause of many accidents as homeowners do not understand the significant forces applied by hydrostatic pressure, this invention uses firstly a door that opens outwards so that unsuspecting homeowners cannot open a door into their own face in the middle of the night and, secondly, the item $\mathrm{H}$ for controlled release of trapped floodwater. Both are important safety features. Furthermore, the controlled ingress through aperture $\mathrm{J}$ as flap $\mathrm{C}$ floats in proportion to the rise of the external floodwater prevents sudden floodwater ingress, which can be another source of accidents. The automatic function of flap $\mathrm{C}$ to let in floodwater will be the point at which the occupants realise that there is nothing more that can be done at the property and, if they already have not, it is time to leave.

Figure 2(a) shows a vertical cross-sectional drawing through the centre lower part of the frame and door during a flood event, when floodwater has reached the critical height $\mathrm{M}$, whereby it may cause structural damage if allowed to rise any further on one side of the external wall. The door B is pivotally attached to the frame $\mathrm{A}$ and is now being forced back against the frame by floodwater pressure exerted on its outside face as shown by arrows $\mathrm{N}$. This increases the force on seal $G$ between door B and frame A to make it more watertight. Similarly, floodwater pressure shown by arrows $\mathrm{N}$ onto lip $\mathrm{E}$ and frame A forces the frame onto the face of brickwork D compressing the seal $\mathrm{F}$ to make it more watertight. The drawing shows that the critical differential height between floor finish $\mathrm{K}$ and surface of floodwater $\mathrm{M}$ has been reached and the floodwater has been automatically allowed to enter the property via aperture $\mathrm{J}$ as flap $\mathrm{C}$ floats and pivots around its attachment to door B. If floodwater rises even higher the buoyant flap $\mathrm{C}$ may be positioned vertically at which point it may detach from its pivotal attachment so that if damaged or punctured by debris it cannot drop back across the aperture $J$ and cause structural damage by not letting floodwater pass through J. As the water level recedes after the flood event is over the floodwater can pass back out of the property via aperture $\mathrm{J}$ and floating flap $\mathrm{C}$ to the lower edge of aperture $\mathrm{J}$. The bung or valve $\mathrm{H}$ can then be used to control safe release of trapped water from the property. 


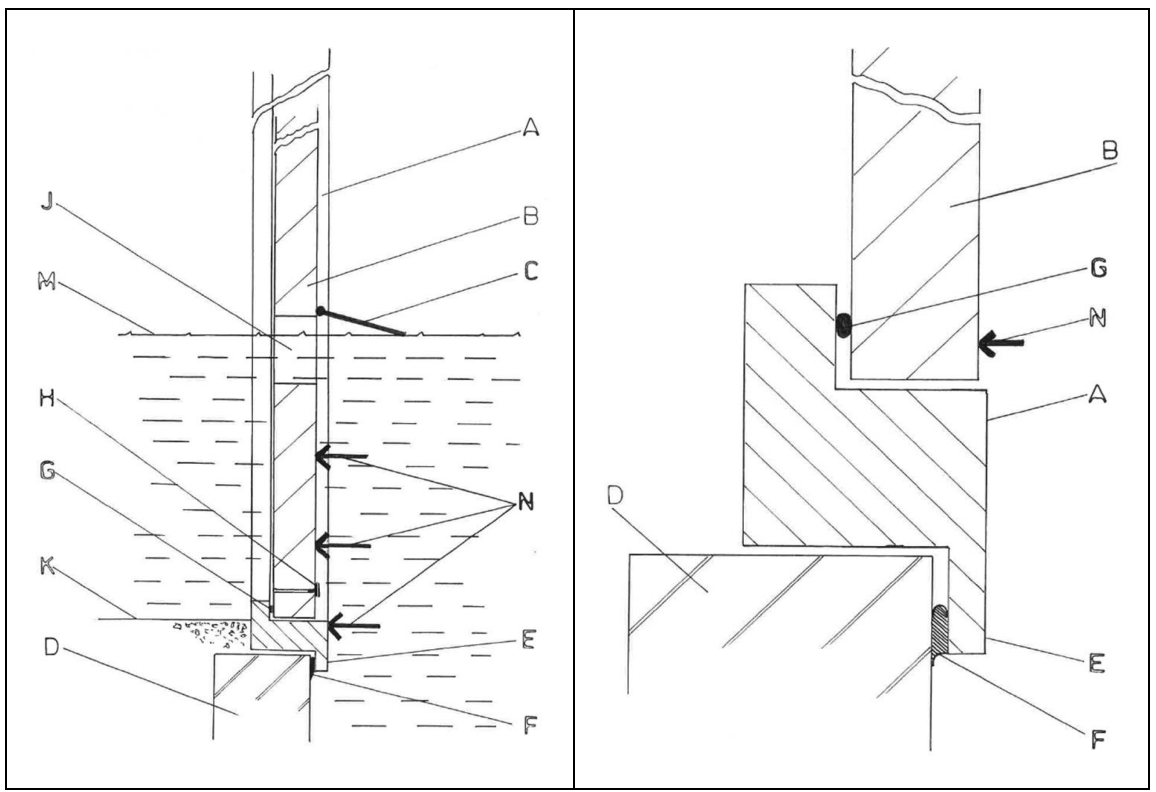

(a)

(b)

Figure 2: Sectional and plan drawings of the safety flood door show (a) vertical cross-sectional (as Figure 1(b)) but with floodwater at the height whereby it has been let into the property through the flap and door aperture; and (b) horizontal cross-sectional of the water seals between brickwork, frame and door.

Figure 2(b) is a detailed horizontal cross-sectional drawing across the jamb of the frame as installed and shows the seals used as part of the construction. The cross-section is a close-up of brickwork D to frame A and frame to door B joins. Door B opens outwards from the property and so water pressure on outside face of door B shown by arrow $\mathrm{N}$ compresses seal $\mathrm{G}$ between frame $\mathrm{A}$ and door B. Similarly, water pressure compresses further the seal $\mathrm{F}$ between frame lip E and external brickwork face. The greater the external floodwater pressure then the better the seal for $G$ and $F$ and the more watertight the installation becomes. Frame A can be attached to brickwork D using conventional fixings, through jamb of frame and into the reveal of brickwork. The additional use of a double rebated door and frame set will reduce installation times as the double rebate design is less prone to leakage and also under external water pressure the double rebate provides a better seal. 


\section{Practical demonstration of the product and its design}

With regard to the much needed development of new and innovative flood protection products, the position of the government was clarified by the EA Chairman's speech at a recent National Flood Forum annual conference: ' $I$ would like to see industry develop new, innovative products that can be installed in homes and businesses to reduce the risk of flooding. Climate change is likely to increase the frequency and severity of flooding, and the UK could be the global market leader on technologies to counter the impacts that it brings'. This is reiterated by the recent DEFRA FD2682 'Low Cost Resilience' project [15]. Hence, in line with policy, the EA launched [16] the UK's largest flood test centre (at HR Wallingford) to test flood products against a new industry standard PAS 1188 for BSI kite-marked status. This facility and the kite-mark scheme offer manufacturers the benefit of demonstrating their products meet the highest standards and display the kite-mark symbol [6].

As a means of demonstrating the new safety flood door and its design, a simple laboratory apparatus was constructed by the researchers to test the practical performance of the new safety flood door (Figure 3(a) and (b)). Whereby, a holding tank on the outward side of the door was filled with floodwater to $600 \mathrm{~mm}$ depth and kept there for several hours (Figure 4(a) and (b)), without leakage entering the inward side of the door. Further floodwater was then added to the holding tank to $>700 \mathrm{~mm}$ depth (Figure 5(a)) and, at this point, the postal flap raised and the floodwater cascaded through the opening and, if this had been a real situation, into the inside of the property (Figure 5(b)).

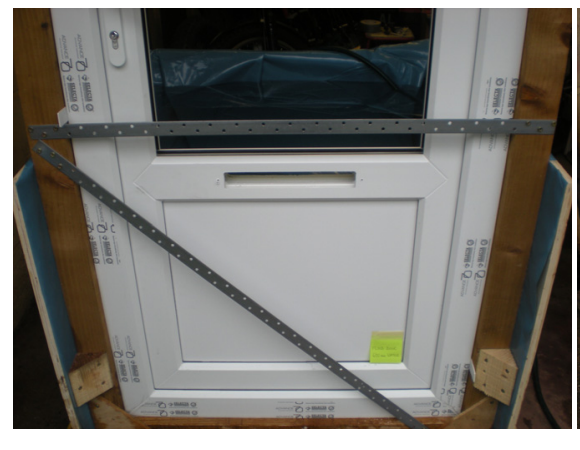

(a)

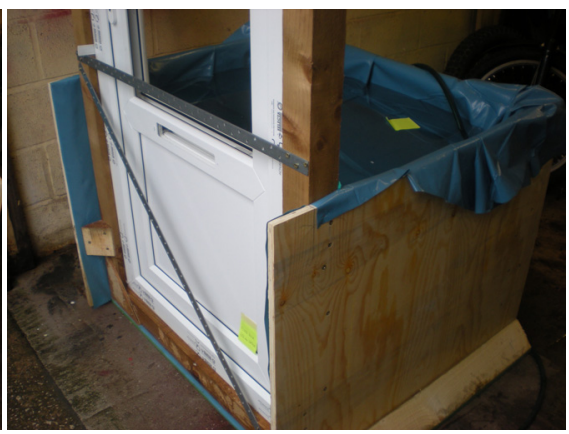

(b)

Figure 3: Photos (a) and (b) present the newly designed flood safety door prepared for practical test conditions, where the door face shown would represent the inside of a property. 


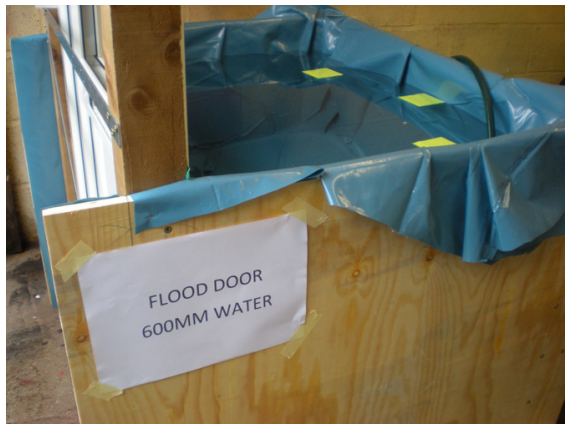

(a)

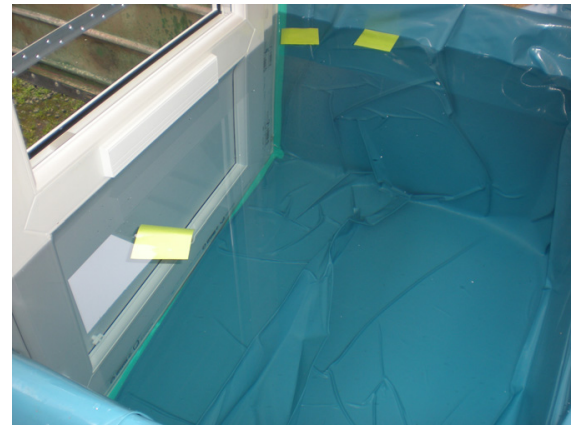

(b)

Figure 4: Photos (a) and (b) show the flood resistant design of the flood safety door under practical test conditions, with $600 \mathrm{~mm}$ depth of floodwater being held outside of a property.

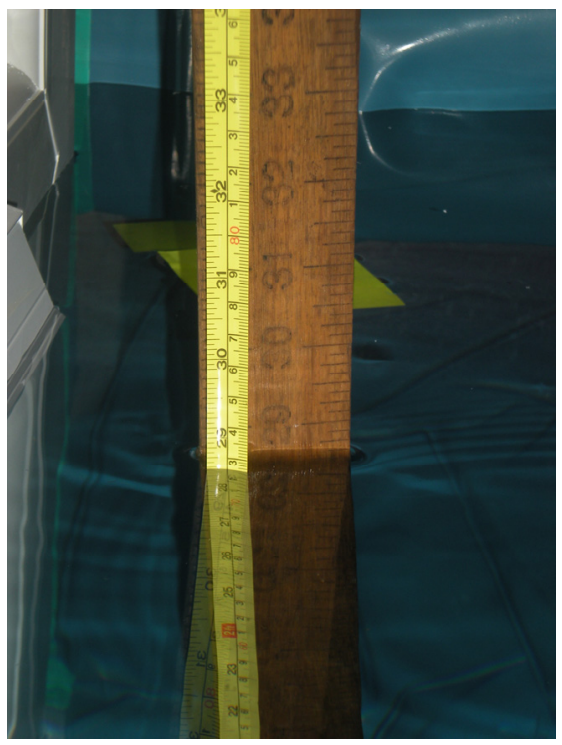

(a)

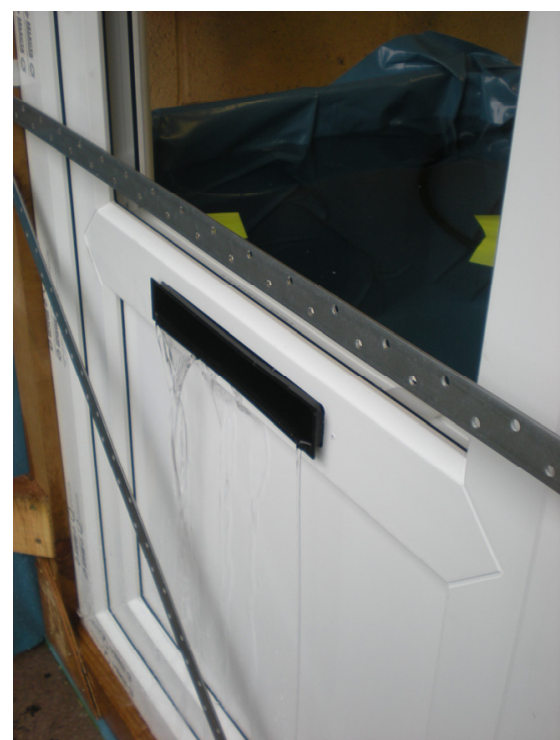

(b)

Figure 5: Photos (a) and (b) illustrate the new safety flood door under practical test conditions exceeding $600 \mathrm{~mm}$ depth and floodwater cascading through the postal hole. 


\section{Discussion}

The new safety flood door offers several improvements and collective benefits over the existing range of commercially available flood doors, namely: external floodwater pressure will act to force the door frame onto the outside face of the brickwork to prevent water leaks; external floodwater pressure will act to force the door onto the door frame to prevent water leaks; during a flood event the door cannot be inadvertently opened by an unsuspecting homeowner and cause an accident; during a flood event the floodwater pressure cannot overcome the door to frame locking mechanism and force the door open into the face of the homeowner; the flood door is in situ and in the event of a flood it does not require any form of deployment; the passive nature of the flood door means that insurers may take its fitment into consideration when determining premiums; the door is of simple construction and, therefore, a cost effective option for the homeowner; the door looks no different to other external doors; the door may prevent structural damage and collapse of the property as water is let in at a predetermined differential height; the predetermined height can be set at any height; the flap used to let floodwater into the property is automatic in operation and needs no deployment by the homeowner; flap and aperture through door can also double up as a postal flap; the buoyant flap can detach completely from the door at high water levels to ensure uninterrupted floodwater ingress; buoyant flap allows floodwater back out of the property as water level recedes; door can be flush with frame or rebated; buoyant flap can be set into a transom or lower part of door; area of door below buoyant flap and aperture for floodwater ingress can be solid to prevent damage by floating debris; a one way safety valve or bung serves to safely let water out from inside the property when it has become trapped after a flood event; and automatic floodwater ingress will prompt occupiers to abandon the property before their rescue becomes too dangerous.

\section{Conclusions}

Recent severe flood events in the UK have illustrated the need to offer improved flood protection to homes and businesses in flood risk areas. The UK Government acknowledges that many buildings cannot be protected from flooding by large-scale flood defence schemes. Therefore, the shift in government strategy transfers some of the responsibility for flood protection from the government to the property owner, who is encouraged to install appropriate measures. The current choice of property level flood protection decision-making lies between flood resistance and resilience measures. Normally, most homeowners' first instinct is to keep floodwater out and resistance products are more popular, supported by kite-marked products and promoted by manufacturers.

This study has presented a new safety flood door and frame that can be fitted into new or existing door apertures, where the double rebated door opens outwards and an automatic safety flap lets in floodwater when the differential height reaches a critical level that may cause structural property damage. The 
water seals at frame to brickwork and door to frame joins will be enhanced by external water pressure from the floodwater and a safety outlet for floodwater trapped inside the building may be fitted. From a commercial and practical perspective, the patent pending product demonstrates several advantages over those of existing flood door designs and systems and, moreover, is an affordable option by comparison to other flood doors.

\section{References}

[1] NAO (National Audit Office). Strategic Flood Risk Management. House of Commons HC-780. (2014).

[2] DEFRA (Department of Environment, Farming and Rural Affairs). Developing the Evidence base for Flood Resistance and Resilience: RandD Technical Report FD2607/TR1. DEFRA: London (2008).

[3] DEFRA (Department of Environment, Farming and Rural Affairs). Adapting to Climate Change. UK Climate Predictions June 2009. DEFRA: London (2009).

[4] DEFRA (Department of Environment, Farming and Rural Affairs). Making Space for Water: Developing a New Government Strategy for Flood and Coastal Erosion Risk Management in England: A Delivery Plan. DEFRA: London (2005).

[5] Treby, E., Clarke, M. \& Preist, S. Confronting flood risk: Implications for insurance and risk transfer. Journal of Environmental Management, 81, 351-359 (2006).

[6] Beddoes, D.W. \& Booth, C.A. Novel solutions to a traditional method of property-level flood protection: technical insights of innovative door aperture guards. In: Marchettini, N., Brebbia, C.A., Pulselli, R. \& Bastianoni, S. (Editors) Sustainable Cities IX, WIT Press, Southampton, 1255-1266 (2014).

[7] Lamond, J.E. The role of market-based flood insurance in maintaining communities at risk of flooding: A SWOT analysis. In: Booth, C.A. \& Charlesworth, S.M. (Editors) Water Resources in the Built Environment: Management Issues and Solutions. Wiley-Blackwells, Oxford, 258-270 (2014).

[8] U.S. Army Corps of Engineers (USACE). Tests of Materials and Systems for Flood Proofing Structures. Washington, DC: U.S. Army Corps of Engineers, p. 89 (1998).

[9] Beddoes, D.W. Safety Door. Pat Pend. 1315021.4. (2014).

[10] OST (The Office of Science and Technology). Future Flooding - Final Report, Foresight Flood and Coastal Defence Project. London: OST (2014).

[11] CIRIA (Construction Industry Research and Information Association) Improving the flood resilience of buildings through improved materials, methods and details, CIRIA Report WP2c. London: CIRIA (2005). 
[12] Beddoes, D.W. \& Booth, C.A. Property level flood resistance versus resilience measures: a novel approach. International Journal of Safety and Security Engineering, 1, 162-181 (2011).

[13] DEFRA (Department of Environment, Farming and Rural Affairs). Consultation on Policy Options for Promoting Property-level Flood Protection and Resilience, Defra: London (2008).

[14] DTLR (Department of Transport, Local Government and the Regions). Department of Transport, Local Government and the Regions Development and Flood Risk. Preparing for Floods - Interim Guidance for Improving the Flood Resistance of Domestic and Small Businesses Properties, TSO: London (2002).

[15] http://sciencesearch.defra.gov.uk/Default.aspx?Menu=Menu\&Module=M ore $\&$ Location $=$ None $\&$ Completed $=0 \&$ ProjectID $=19221$ [Cited 23rd March 2016].

[16] http://www.environment-agency.gov.uk/static/media/National_Flood Forum_speech_Feb_2010.final.pdf [Cited 24th October 2010]. 